Supporting Information for

\title{
Structural characterization of aluminum (oxy)hydroxide films at the muscovite (001) - water interface
}

\author{
Sang Soo Lee ${ }^{* \dagger}$, Moritz Schmidt ${ }^{\dagger}$, Timothy T. Fister $^{\dagger}$, Kathryn L. Nagy ${ }^{\ddagger}$, Neil C. Sturchio ${ }^{\ddagger}$, and Paul Fenter ${ }^{\dagger}$ \\ ${ }^{\dagger}$ Chemical Sciences and Engineering Division, Argonne National Laboratory, 9700 South Cass Avenue, Argonne, IL 60439, \\ United States \\ ${ }^{\star}$ Department of Earth and Environmental Sciences, 845 West Taylor Street, MC-186, University of Illinois at Chicago, Chicago, \\ IL 60607, United States \\ *Corresponding author: phone: (630)252-6679; fax: (630)252-9570; e-mail: sslee@anl.gov
}

\section{SI-1. Structure of aluminum (oxy)hydroxide and oxide phases}

The specular crystal truncation rod (CTR) data showed formation of a single-layer aluminum hydroxide film at the muscovite $(001)-100 \mu \mathrm{M} \mathrm{AlCl}_{3}$ solution interface at $\mathrm{pH}$ 4.2. The film is composed of three atomic planes aligned parallel to the muscovite (001) surface. The distances between two adjacent planes match those of gibbsite-layer structure projected from the side of its (001) plane. The thermodynamic calculations suggested that the solution was supersaturated with respect to gibbsite, $\alpha$ $\mathrm{Al}(\mathrm{OH})_{3}$, and diaspore, $\alpha-\mathrm{AlOOH}$. In this section, we show the crystallographic structures of major $\mathrm{Al}$ oxide, hydroxide, and oxyhydroxide minerals, and compare them with the CTR-derived structure.

Gibbsite, $\alpha-\mathrm{Al}(\mathrm{OH})_{3}$, is composed of planes of $\mathrm{Al}$ sandwiched between two sheets of hexagonally packed hydroxyls (Fig. S1a). ${ }^{1}$ Every two out of three octahedral sites are occupied with Al while the other one remains vacant. Sectional views perpendicular to the (001) plane show three parallel planes of atoms $(\mathrm{O}-\mathrm{Al}-\mathrm{O})$ within one layer. The distance between two adjacent planes is around $1 \AA$ consistent with those from the XR analyses.

Diaspore, $\alpha-\mathrm{AlO}(\mathrm{OH})$, is composed of strips of octahedrally-coordinated $\mathrm{Al}$ ions, the direction of which defines the crystallographic c axis. ${ }^{1}$ Each strip has the width of two edge-sharing octahedra (Fig. S1b). Sectional views perpendicular to the (100) plane show sheets composed of two planes of oxygen atoms (or hydroxyl groups) whose distance along the 100 direction is $\sim 0.36 \AA$ and aluminum ions that are also distributed at two crystallographic heights. If the film observed from the X-ray reflectivity measurements was that of diaspore, these pairs of oxygen and $\mathrm{Al}$ planes would not be resolvable and therefore would be shown as two broader peaks in the total electron-density profile. In contrast, the bestfit model showed that the electron-density peaks within the film have intrinsically narrow distribution widths $(\leq 0.1 \AA)$. 
(a) Gibbsite, $\alpha-\mathrm{Al}(\mathrm{OH})_{3}$

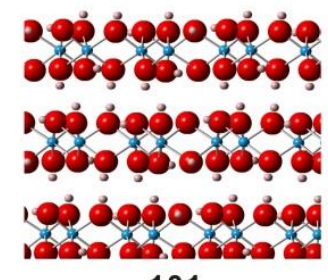

101

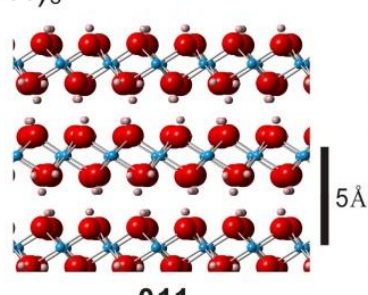

011 (b) Diaspore, $\alpha-\mathrm{AIO}(\mathrm{OH})$

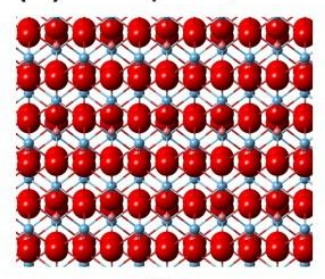

101

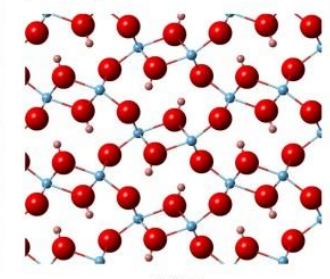

110

(c) Boehmite, $\gamma$-AIO $(\mathrm{OH})$

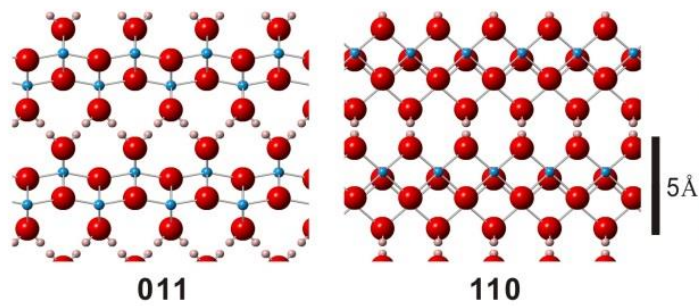

(d) Corundum, $\alpha-\mathrm{Al}_{2} \mathrm{O}_{3}$

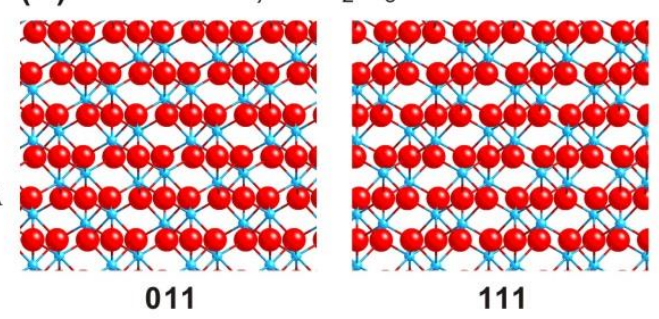

Figure S1. Chemical composition and crystallographic structure of (a) gibbsite, (b) diaspore, (c) boehmite, and (d) corundum. For each crystal, two side views are shown from the perspective that makes the crystal structure most similar to that observed in the X-ray results. The hkl indices of the corresponding side plane are shown under each figure. The vertical directions correspond to 001, 100, 010, and 011 directions for gibbsite, diaspore, boehmite, and corundum, respectively. Color coding: H: pink, O: red, Al: cyan.

Boehmite, $\gamma-\mathrm{AlO}(\mathrm{OH})$, contains double sheets of octahedra with $\mathrm{Al}$ ions at their centers. Sectional views perpendicular to its (010) plane show one double-octahedral layer consists of four atomic planes (Fig. S1c). The top and bottom planes are composed of hydroxyl groups in which hydrogen atoms can be placed in two crystallographic locations (note that the hydrogen atoms depicted in Fig. S1c are determined to have $1 / 2$ site occupancies). ${ }^{2}$ Two middle planes are composed of $\mathrm{Al}$ and oxygen atoms. The overall thickness of the layer, i.e., $\mathrm{O}^{-} \mathrm{O}$ distance between two hydroxyl groups, is $\sim 4.1 \AA$, larger than the distance $(\sim 2 \AA)$ determined from the XR analyses.

Corundum, $\alpha-\mathrm{Al}_{2} \mathrm{O}_{3}$, has oxygen atoms approximately in the arrangement of hexagonal closest packing within which two-thirds of octahedral sites are occupied by Al (Fig. S1d). Sectional views perpendicular to its (011) plane are similar to that of gibbsite (001) plane with the distance between the top and bottom oxygen planes of $\sim 2.2 \AA$ [c.f., $~ 2.0-2.1 \AA$ for gibbsite (001)]. However, Al ions are located at two different crystallographic heights (separated by $0.5 \AA$ ) within the layer, different from the film structure observed from the XR measurement. In addition, the thermodynamic calculations (Table 1 of the manuscript) indicate that the solution was undersaturated with respect to this mineral. 


\section{SI-2. Experimental details}

SI-2.1. Experimental Solutions. We prepared $0.1 \mathrm{M} \mathrm{AlCl}_{3}$ and $\mathrm{GaCl}_{3}$ stock solutions by dissolving high purity aluminum or gallium chloride salts (>99.99\%; Sigma Aldrich Inc.) in hydrochloric acid (0.01 M and 0.1 M, respectively). These two stock solutions were used to prepare experimental solutions less than $24 \mathrm{~h}$ before reaction with the muscovite mica. The $\mathrm{pH}$ of the solutions was adjusted using $0.01-0.1 \mathrm{M}$ $\mathrm{NaOH}$. For the $\left(\mathrm{Al}_{0.9} \mathrm{Ga}_{0.1}\right) \mathrm{Cl}_{3}$ experiment, the low $\mathrm{Ga}$ concentration was used to minimize changes in the interfacial structure compared to the pure $\mathrm{AlCl}_{3}$ solution while keeping the total trivalent cation concentration constant. The 9:1 ratio was determined based on a preliminary X-ray experiment. This experiment was conducted using a solution with $[\mathrm{Al}]=99 \mu \mathrm{M}$ and $[\mathrm{Ga}]=1 \mu \mathrm{M}$. The RAXR data for the muscovite (001) reacted with the solution for $\sim 8 \mathrm{~h}$ showed the presence of Ga sorbed at the interface. But, the magnitudes of the RAXR signals were very small (1-2\% of the intensity).

Time-dependent changes of a $100 \mu \mathrm{M} \mathrm{AlCl}$ s solution at $\mathrm{pH} 4.2$ were monitored to quantify the homogeneous nucleation (i.e., without a muscovite crystal). Four $\mathrm{mL}$ of solution was sampled from $\sim 150 \mathrm{~mL}$ of the solution at each time step $(t=0,2,8,25,95,270 \mathrm{~h})$. The sampled solutions were filtered using a $0.1 \mu$ membrane, and the total $\mathrm{Al}$ concentrations were measured using inductive coupled plasma mass spectrometry. The results show that the change was relatively small, indicating that the homogeneous nucleation rates were low although the solution was supersaturated with respect to diaspore and gibbsite. In addition, each sample was kept vertical to minimize any possible gravitational deposition of solid phases during the reaction.

The CTR data measured after $2000 \mathrm{~h}$ reaction in the $\mathrm{AlCl}_{3}$ solution show the formation of a thick diaspore film, indicating that a fraction of $\mathrm{Al}$ ions in the reacting solution was removed. The amount of $\mathrm{Al}$ needed for the formation of a $600-\AA$ thick diaspore film that fully covers the muscovite crystal corresponds to $\sim 20 \%$ of the total $\mathrm{Al}$ content in $50 \mathrm{~mL}$ of a $100 \mu \mathrm{M} \mathrm{AlCl}$ solution. Although three $50 \mathrm{~mL}$ of $\mathrm{AlCl}_{3}$ solutions were used for this experiment, it is expected that the solution chemistry changed during the reaction. Specifically, the saturation

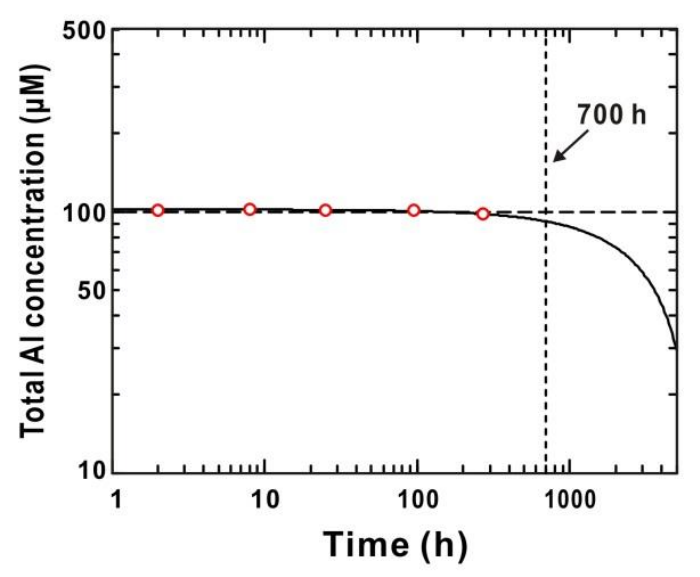

Figure S2. Time-dependent change in the total $\mathrm{Al}$ concentration in a $100 \mu \mathrm{M} \mathrm{AlCl}_{3}$ solution at $\mathrm{pH}$ 4.2. The data measured at $t=0,[\mathrm{Al}]_{\mathrm{tot}}=104 \mu \mathrm{M}$, is not shown. The solid line is the linear regression of the data $\left(\mathrm{R}^{2}=\right.$ 0.7). The long-dashed horizontal line represents the nominal Al concentration of the solution. The shortdashed vertical line indicates the approximately longest time applied for reaction of a mica crystal with a $\mathrm{AlCl}_{3}$ solution. 
indices of $\mathrm{Al}$ (oxy)hydroxide phases could decrease slightly. For example, we observed that the solution $\mathrm{pH}$ was almost constant after the reaction, and the thermodynamic calculations suggested that the mineral saturation indices for diaspore and gibbsite would be 1.5 and 0.6, respectively (compared with 1.6 and 0.7 for the initial solution, Table 1).

SI-2.2. X-ray reflectivity measurements. X-ray data were collected at beamlines 6-ID-B, 11-ID-D, and 33-ID-D, Advanced Photon Source (APS) (Table S1). At 6-ID-B, monochromatic incident X-ray beam collimated by $0.3 \mathrm{~mm}$ (vertical, $v$ ) $\times 1.0 \mathrm{~mm}$ (horizontal, $h$ ) slits was focused vertically by a Kirkpatrick-Baez $(\mathrm{KB})$ mirror. The focused beam had a size of $0.04 \mathrm{~mm}(v) \times 1.0 \mathrm{~mm}(h)$ on the sample with a flux of $\sim 1 \times 10^{12}$ photon/sec. At 11-ID-D, monochromatic X-ray beam reflected from a toroidal mirror, with the beam size of $0.4 \mathrm{~mm}(v) \times 0.5 \mathrm{~mm}(h)$ was further focused vertically using a KB mirror. The final beam had a size of $0.08 \mathrm{~mm}(v) \times 0.5 \mathrm{~mm}(h)$ on the sample with a flux of $6 \times 10^{12}$ photon/sec. At 33-ID-D, the incident beam size was defined by slits $[0.2 \mathrm{~mm}(v) \times 1.0 \mathrm{~mm}(h)]$ and had a flux of $\sim 3 \times 10^{11}$ photons/sec.

\begin{tabular}{llll}
\hline \multicolumn{3}{l}{ Table S1. Experimental setup for the CTR measurements. } \\
\hline Experiments & beamline & Photon energy (keV) & X-ray wavelength $(\AA)$ \\
$\mathrm{AlCl}_{3}$ for $18 \mathrm{~h}$ & 11-ID-D & 11.50 & 1.078 \\
$\mathrm{AlCl}_{3}$ for $2000 \mathrm{~h}$ & 33-ID-D & 16.00 & 0.775 \\
$\left(\mathrm{Al}_{0.9} \mathrm{Ga}_{0.1}\right) \mathrm{Cl}_{3}$ for $12 \mathrm{~h}$ & 6-ID-B & 14.00 & 0.886 \\
$\mathrm{Beam} \mathrm{effect}(S e c t i o n ~ S I-3)$ & 33-ID-D & 13.05 & 0.950 \\
\hline
\end{tabular}

SI-2.3. Crystal truncation rod. The CTR data were fit to a structural model consisting of rigid bulk muscovite; the interfacial region including muscovite surface atoms, precipitates, and sorbed species; and the bulk solution above the interfacial region. The distribution of individual atomic planes within precipitate layers was modelled using Gaussian peaks, each of which was defined by an occupancy $\left(o_{\mathrm{j}}\right.$, expressed in units of water equivalents, $\left.W_{\mathrm{eq}}\right),{ }^{3}$ height or position above the muscovite surface oxygen atoms $\left(z_{\mathrm{j}}\right)$, and root-mean-square (rms) distribution width $\left(u_{\mathrm{j}}\right)$. Using this structural model, non-resonant $\mathrm{X}$-ray reflectivity, $R$, measured by CTR can be calculated as

$$
R \propto\left(4 \pi \mathrm{r}_{\mathrm{e}} / q A_{\mathrm{UC}}\right)^{2}\left|F_{\mathrm{NR}}\right|^{2}
$$

where $\mathrm{r}_{\mathrm{e}}=2.818 \times 10^{-5} \AA$ is the radius of an electron, $q$ is the momentum transfer, $A_{\mathrm{UC}}=46.72 \AA^{2}$ is the unit cell area of the muscovite (001) plane, and $F_{\mathrm{NR}}$ is the non-resonant structure factor, ${ }^{4}$ and can be calculated using a parameterized structural model as, 


$$
\mathrm{F}_{\mathrm{NR}}=F_{\mathrm{UC}} F_{\mathrm{CTR}}+F_{\mathrm{INT}}+F_{\mathrm{W}}
$$

where $F_{\mathrm{UC}}, F_{\mathrm{INT}}$, and $F_{\mathrm{W}}$ are the structure factors of a muscovite unit cell, interfacial region, and fluid water, respectively, and $F_{\mathrm{CTR}}=1 /[1-\exp (-i q d / 2)]$ is the crystal truncation rod form factor where $d=$ $\sim 19.96 \AA$ is muscovite's (001) layer spacing. The structure factor of a given sub-layer is defined as

$$
F_{\mathrm{i}}=\Sigma_{\mathrm{j}} o_{\mathrm{j}} f_{\mathrm{j}}(q) \exp \left(i q z_{\mathrm{j}}\right) \exp \left[-\left(q u_{\mathrm{j}}\right)^{2} / 2\right]
$$

where $f_{\mathrm{j}}(q)$ is the atomic scattering factor, ${ }^{5}$ and $o_{\mathrm{j}}, \mathrm{z}_{\mathrm{j}}$, and $u_{\mathrm{j}}$ are the occupancy, height from the top oxygen plane of the muscovite surface, and distribution width of a $\mathrm{j}^{\text {th }}$ atom, respectively. The structure of bulk

\begin{tabular}{|c|c|c|c|c|c|c|c|c|c|}
\hline Solutions & \multicolumn{3}{|c|}{$\mathrm{AlCl}_{3}$ for $18 \mathrm{~h}$} & \multicolumn{3}{|c|}{$\mathrm{AlCl}_{3}$ for $2000 \mathrm{~h}$} & \multicolumn{3}{|c|}{$\left(\mathrm{Al}_{0.9} \mathrm{Ga}_{0.1}\right) \mathrm{Cl}$ for $12 \mathrm{~h}$} \\
\hline$\chi^{2} /$ R-factor & \multicolumn{3}{|c|}{$1.18 / 0.036$} & \multicolumn{3}{|c|}{$1.03 / 0.047$} & \multicolumn{3}{|c|}{1.04 / 0.043} \\
\hline Parameters & $z$ & 0 & $u$ & $z$ & 0 & $u$ & $z$ & 0 & $u$ \\
\hline Peak 1 & $1.49(5)$ & $1.35(12)$ & $0.10(f)$ & $1.53(15)$ & $0.59(11)$ & $0.10(f)$ & $1.42(4)$ & $1.32(8)$ & $0.10(f)$ \\
\hline Peak 2 & $2.64(2)$ & $4.36(15)$ & $0.10(f)$ & $2.68(5)$ & $3.09(11)$ & $0.10(f)$ & $2.55(1)$ & $3.80(10)$ & $0.10(f)$ \\
\hline Peak 3 & $3.79(1)$ & $4.41(6)$ & $0.10(f)$ & $3.67(10)$ & $2.88(14)$ & $0.15(f)$ & $3.59(2)$ & $3.18(5)$ & $0.10(f)$ \\
\hline Peak 4 & $4.88(2)$ & $3.95(24)$ & $0.10(f)$ & $4.81(6)$ & $3.7(13)$ & $0.32(13)$ & $4.81(1)$ & $5.18(26)$ & $0.41(2)$ \\
\hline Peak 5 & $7.46(5)$ & $1.75(34)$ & $0.22(9)$ & $7.38(2)$ & $1.89(64)$ & $0.25(12)$ & $7.27(4)$ & $1.14(8)$ & $0.10(f)$ \\
\hline Peak 6 & $9.03(21)$ & $2.39(80)$ & $0.72(20)$ & $7.22(30)$ & $10.8(17)$ & $1.86(52)$ & $8.77(5)$ & $3.36(32)$ & $0.73(7)$ \\
\hline \multicolumn{4}{|l|}{ Peak 7} & $11.79(5)$ & $2.79(39)$ & $0.61(4)$ & & & \\
\hline \multicolumn{4}{|l|}{ Peak 8} & $15.19(14)$ & $11.06(96)$ & $3.33(36)$ & & & \\
\hline \multicolumn{4}{|l|}{ Peak 9} & $24.00(82)$ & $1.60(53)$ & $2.59(48)$ & & & \\
\hline
\end{tabular}
water was expressed by a layered-water model. ${ }^{6,7}$

The best-fit model (Table S2) was chosen on the basis of the smallest $\chi^{2}$ defined as

$$
\chi^{2}=\left[\Sigma_{\mathrm{k}}\left(I_{\mathrm{k}}-I_{\text {calc, } \mathrm{k}}\right)^{2} / \sigma_{\mathrm{k}}^{2}\right] /\left(N-N_{\mathrm{p}}\right)
$$

where $N$ and $N_{\mathrm{p}}$ are the numbers of data points and parameters used in the model fit, respectively, $I_{\mathrm{k}}$ and $I_{\text {calc, } \mathrm{k}}$ are the measured and calculated reflected intensities, respectively, and $\sigma_{\mathrm{k}}$ is the uncertainty of the $\mathrm{k}^{\text {th }}$ data point. We also considered the covariance among fitting parameters ${ }^{8}$ to determine the optimal number of model parameters. The $R$-factor $\left(\Sigma_{\mathrm{k}}\left|\left(I_{\mathrm{k}}-I_{\text {calc, } \mathrm{k}}\right) / I_{\mathrm{k}}\right| / N\right)$ of the best-fit is also reported for comparison. 

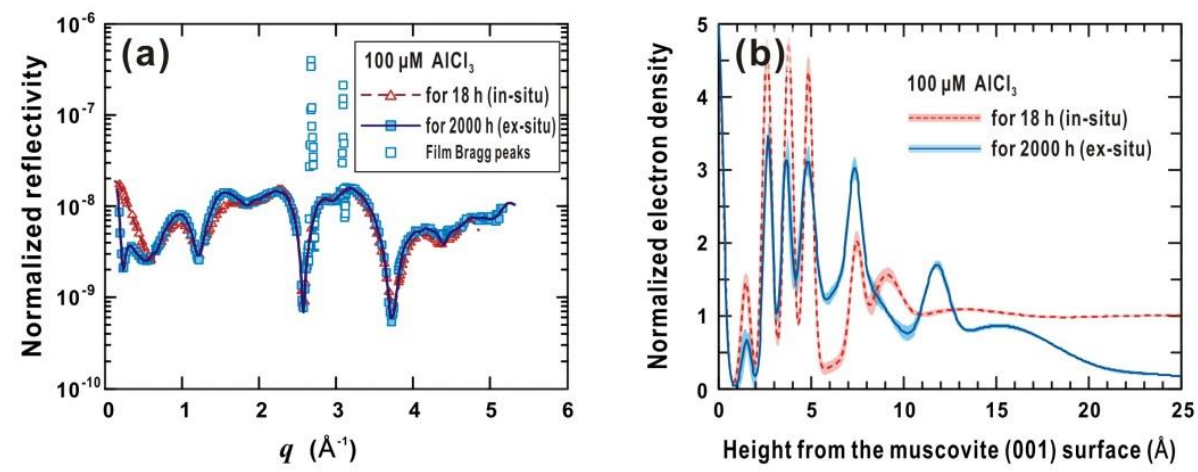

Figure S3. In-situ high-resolution X-ray reflectivity data at the muscovite and $100 \mu \mathrm{M} \mathrm{AlCl} 3$ solution interface. (a) Normalized CTR from the muscovite (001) surface reacted with a $100 \mu \mathrm{M} \mathrm{AlCl}_{3}$ solution at $\mathrm{pH} 4.2$ for 18 and $2000 \mathrm{~h}$. The dashed and solid lines through the data points are calculated from the best-fit models for these two data sets, respectively. For the data collected after $2000 \mathrm{~h}$ reaction, the data points near the diaspore film Bragg peaks (Fig. 2) were excluded during the analyses. (b) The total electron-density profiles derived from the best-fit models of the CTR data shown in (a).

SI-2.4. Resonant Anomalous X-ray Reflectivity. The RAXR data (Fig. S4) were measured for the $\left(\mathrm{Al}_{0.9} \mathrm{Ga}_{0.1}\right) \mathrm{Cl}_{3}$ data. During this experiment, the stability of the interfacial system was monitored by periodically measuring RAXR at $q$ value of $0.38 \AA^{-1} .{ }^{9}$ Whenever a significant change in the RAXR spectra was observed, the sample was translated parallel to the surface so that new data could be measured at a fresh spot. The reproducibility of the system was ascertained by replicating an RAXR spectrum at $q=0.38 \AA^{-1}$, after which a new set of measurements were resumed. The only exceptions were the data measured at the highest $q$ values ( 3.84 and $4.33 \AA^{-1}$ ), which were obtained at a fresh spot but without measuring an RAXR at $q=0.38 \AA^{-1}$. These data were measured with longer exposure time (7 and $4 \mathrm{~min}$, respectively) than the others (i.e., a typical exposure time of less than $1 \mathrm{~min}$ for one RAXR scan). A complete set of RAXR data was obtained in about 6 hours over 8 different spots on one sample.

The measured RAXR intensity is proportional to the squared value of the amplitude of the total structure factor $\left(F_{\text {tot }}\right)$. The total structure factor can be expressed as the sum of non-resonant and resonant structure factors $\left[F_{\mathrm{NR}}\right.$ (eq. S2) and $F_{\mathrm{R}}$, respectively]. The $F_{\mathrm{R}}$ can be divided into the $E$-dependent anomalous dispersion term and $q$-dependent partial structure factor, $F\left(q_{x}\right)$, of a resonant atom at the interface. ${ }^{9}$ The $E$-dependent anomalous dispersion, $f^{\prime}(E)+i f^{\prime \prime}(E)$, was determined by using the differential Kramers-Kronig transform ${ }^{11}$ of the Ga $K$-edge X-ray absorption near-edge structure measured in transmission mode through a $0.1 \mathrm{M} \mathrm{GaCl}_{3}$ solution (Fig. S5). The partial structure factor of interfacial $\mathrm{Ga}(\mathrm{III})$ was derived using four different models including 2 to 5 Gaussian peaks (Table S3), and the bestfit model (Fig. 4) was chosen based on the quality of fit (i.e., $\chi^{2}$ ). We compared the fitting results with that from model-independent analysis. ${ }^{9}$ In this analysis each RAXR spectrum was expressed using an amplitude $\left(A_{\mathrm{R}}\right)$ and a phase $\left(\Phi_{\mathrm{R}}\right),{ }^{9}$ and these derived $A_{\mathrm{R}}$ and $\Phi_{\mathrm{R}}$ values were compared with those calculated from the model structures (Fig. S6). 

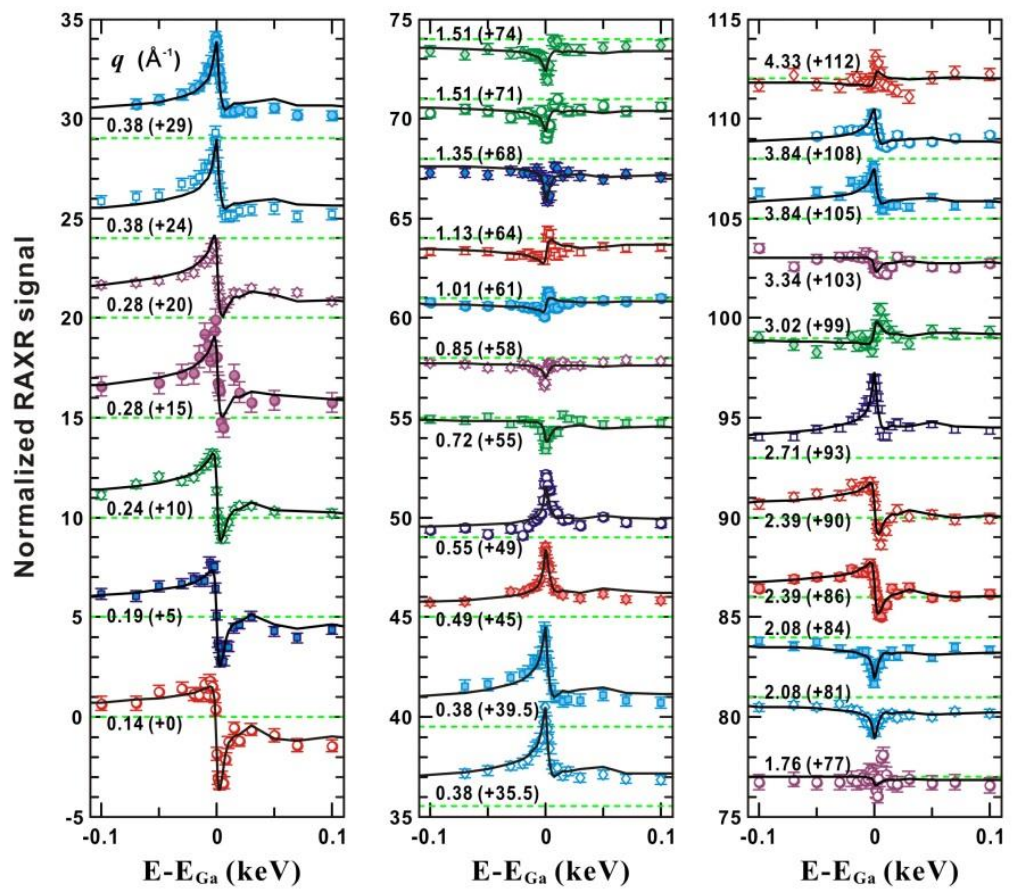

Figure S4. Resonant anomalous X-ray reflectivity (RAXR) of muscovite (001) in a $90 \mu \mathrm{M} \mathrm{AlCl}_{3}+10 \mu \mathrm{M}$ $\mathrm{GaCl}_{3}$ solution at $\mathrm{pH} 4.2$ measured near the Ga $K$-absorption edge energy ( $\mathrm{E}_{\mathrm{Ga}}$ ). The spectra are normalized based on the resonant amplitude normalization method ${ }^{10}\left(\left|F_{\text {tot }}(q, E)\right|^{2}-\left|F_{\mathrm{NR}}(q)\right|^{2}\right) /\left(2\left|F_{\mathrm{NR}}(q)\right|\right)$, where $F_{\text {tot }}$ and $F_{\mathrm{NR}}$ are total and non-resonant structure factors, respectively. Each spectrum is labeled with the $q$ value $\left(\AA^{-1}\right)$ where the spectrum was measured and the vertical offset. The RAXR data measured at the same $q$ are plotted in the same color and shape, while solid and open symbols are used alternatively for clarity. The solid lines through data points are calculated intensities derived from the best-fit models and dashed green horizontal lines indicate the theoretical normalized reflectivity when there is no adsorbed $\mathrm{Ga}(\mathrm{III})$ at the interface.

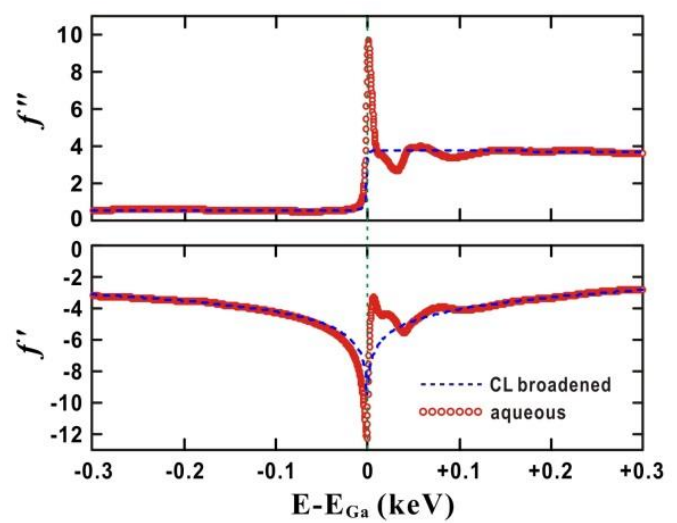

Figure S5. The resonant anomalous dispersion terms $\left(f^{\prime}\right.$ and $\left.f^{\prime \prime}\right)$ for the $\mathrm{Ga}(\mathrm{III})$ aqueous species compared to the spectra derived from the CromerLiberman (CL) calculation for a bare Ga atom ${ }^{12}$ and broadened by energy resolution $(\sim 1 \mathrm{eV})$. 
Table S3. Fitting models for the $\left(\mathrm{Al}_{0.9} \mathrm{Ga}_{0.1}\right) \mathrm{Cl}_{3} \mathrm{RAXR}$ data.

\begin{tabular}{|c|c|c|c|c|c|c|c|}
\hline Models & $\chi^{2}$ (R-factor) & Parameters & Peak 1 & Peak 2 & Peak 3 & Peak 4 & Peak 5 \\
\hline \multirow{3}{*}{ 2-peak A } & \multirow{3}{*}{$\begin{array}{l}4.61 \\
(0.018)\end{array}$} & $z$ & $3.79(3)$ & & $8.56(3)$ & & \\
\hline & & 0 & $0.122(7)$ & & $0.240(10)$ & & \\
\hline & & $u$ & $0.10(f)$ & & $0.40(3)$ & & \\
\hline \multirow{3}{*}{ 2-peak B } & \multirow{3}{*}{$\begin{array}{l}3.05 \\
(0.014)\end{array}$} & $z$ & & $5.37(6)$ & $8.67(2)$ & & \\
\hline & & 0 & & $0.257(13)$ & $0.216(9)$ & & \\
\hline & & $u$ & & $1.11(9)$ & $0.30(3)$ & & \\
\hline \multirow{3}{*}{ 3-peak } & \multirow{3}{*}{$\begin{array}{l}2.72 \\
(0.013)\end{array}$} & $z$ & $3.74(3)$ & $5.78(4)$ & $8.64(2)$ & & \\
\hline & & 0 & $0.097(6)$ & $0.173(9)$ & $0.227(8)$ & & \\
\hline & & $u$ & $0.10(f)$ & $0.56(5)$ & $0.40(3)$ & & \\
\hline \multirow{3}{*}{ 4-peak } & \multirow{3}{*}{$\begin{array}{l}1.79 \\
(0.011)\end{array}$} & $z$ & $3.72(2)$ & $5.76(3)$ & $8.56(2)$ & $11.37(42)$ & \\
\hline & & 0 & $0.118(5)$ & $0.187(16)$ & $0.173(14)$ & $0.296(40)$ & \\
\hline & & $u$ & $0.10(f)$ & $0.58(5)$ & $0.28(4)$ & $3.05(37)$ & \\
\hline \multirow{3}{*}{ 5-peak } & \multirow{3}{*}{$\begin{array}{l}1.68 \\
(0.011)\end{array}$} & $z$ & $3.72(2)$ & $5.80(4)$ & $8.57(2)$ & $10.89(10)$ & $13.76(117)$ \\
\hline & & 0 & $0.122(5)$ & $0.208(18)$ & $0.210(17)$ & $0.073(20)$ & $0.248(76)$ \\
\hline & & $u$ & $0.10(f)$ & $0.64(5)$ & $0.35(3)$ & $0.59(13)$ & $4.14(96)$ \\
\hline
\end{tabular}

$z$ : Height $(\AA)$ from the muscovite surface, $o$ : occupancy (atom/Auc), $u$ : rms width $(\AA)$.

The numbers in parentheses indicate the standard deviation of the last digits of the fitting parameters.

f: fixed during fitting
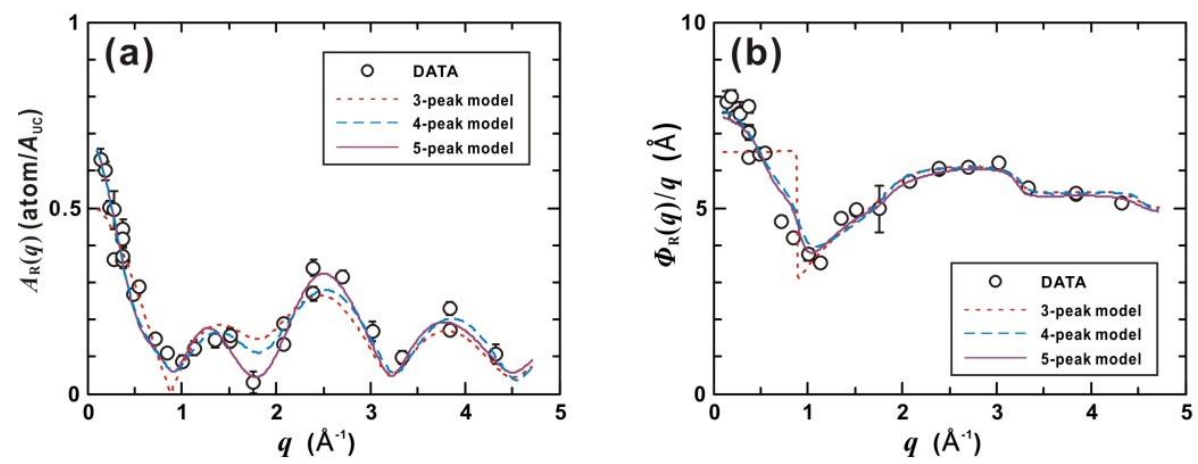

Figure S6. Variation of the partial structure factor amplitude, $A_{\mathrm{R}}(q)$, and phase, $\Phi_{\mathrm{R}}(q) / q$, of $\mathrm{Ga}$ (III) distributed at the muscovite (001) surface in a $90 \mu \mathrm{M} \mathrm{AlCl}_{3}$ and $10 \mu \mathrm{M} \mathrm{GaCl}_{3}$ solution at pH 4.2 determined by the model-independent analyses (data points) compared to values calculated from three different models (see Table S3). The results from 2-peak models are not shown. Both 4-peak and 5-peak models reproduce well the data points except ones at $q=1.76 \AA^{-1}$ with which the latter shows a better agreement than the former. The result from the 4-peak model is shown in the manuscript because of its similarity to but simplicity than the 5-peak model.

\section{SI-3. Beam-induced changes at the interface}

Before the actual measurements we conducted a set of preliminary measurements to check the sensitivity of the interface, in particular the gibbsite-layer film, to X-rays. For example, we repeatedly 
measured reflectivity at a fixed $q=0.85 \AA^{-1}$ (corresponding to $L=2.7$ ) during one CTR measurement ( $\sim 15$ minutes of total X-ray exposure). The result showed time-dependent decreases in intensity ( 25\%), indicating beam-induced change at the interface. This effect can be more significant for higher $q$ data, where larger incident angles result in smaller illuminated areas on the sample, thereby higher photon densities.

We quantified this beam-induced effect by consecutively measuring three CTR data sets at one spot (Fig. S7). The in-situ data were collected on a muscovite sample reacted with $1 \mathrm{mM} \mathrm{AlCl} 3$ solution at $\mathrm{pH}$ 4 for $8 \mathrm{~h}$. The data show significant change in reflectivity especially at $q<2.5 \AA^{-1}$. In particular, increased X-ray exposure leads to decreased amplitude of oscillatory features (e.g., decreased depth of a reflectivity minimum at $q=\sim 1.2 \AA^{-1}$; Fig. S7).
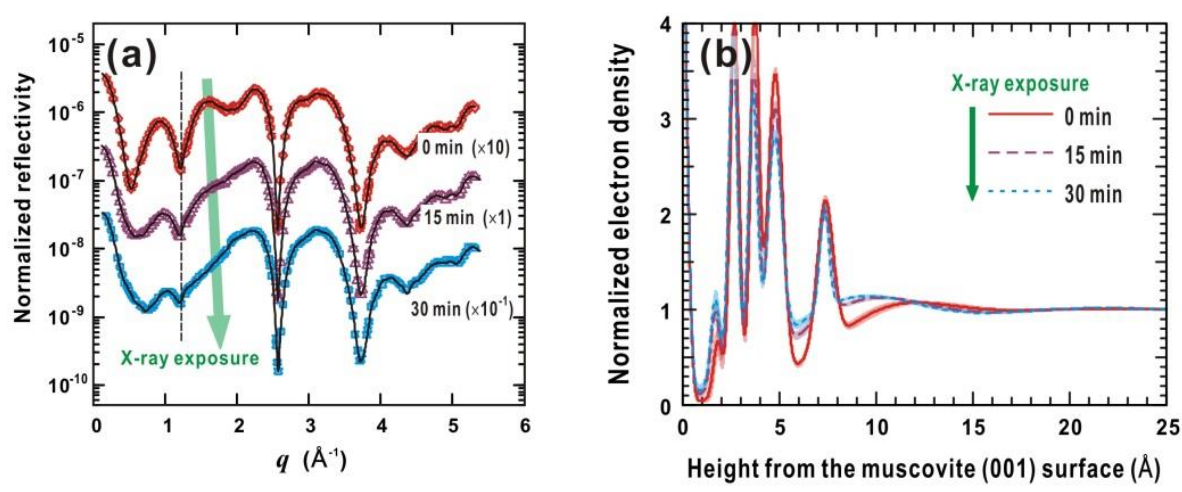

Figure S7. X-ray beam effect on the $\mathrm{Al}(\mathrm{OH})_{3}$ films formed at the muscovite (001)-solution interface. (a) Three normalized CTR data measured sequentially at one spot on a crystal. Each data set is labelled with the duration of X-ray exposure (excluding time for operating the diffractometer for changing angles) before each measurement started. The data are offset vertically for clarity. (b) The total electron-density profiles derived from the best-fit models of the CTR data shown in (a).

The analyses of the CTR data indicate that X-ray radiation decreases the film coverage. The best-fit models (note that a simpler model was used for this specific dataset) show that the sum of the occupancies of the three electron-density peaks in the first gibbsite layer (i.e., peaks $2-4$ in Table S4) decreases by $~ 18 \%$ and $\sim 26 \%$ for the second and third measurements, respectively, compared to the first measurement. This decrease in occupancy indicates that the (areal) coverage of the film decreased. At the same time, the occupancy of the small peak at $\sim 1.7-1.8 \AA$ increased. We interpreted this small peak to be composed of mainly adsorbed water molecules in the ditrigonal cavities of the muscovite surface (see the manuscript), and its increased occupancy can result from the decreased film coverage (e.g., increased porosity of the film). 


\begin{tabular}{|c|c|c|c|c|c|c|c|c|c|}
\hline Exposure & \multicolumn{3}{|l|}{$0 \mathrm{~min}$} & \multicolumn{3}{|l|}{$15 \mathrm{~min}$} & \multicolumn{3}{|l|}{$30 \mathrm{~min}$} \\
\hline$\chi^{2} /$ R-factor & \multicolumn{3}{|c|}{$0.53 / 0.031$} & \multicolumn{3}{|c|}{0.57 / 0.030} & \multicolumn{3}{|c|}{$0.80 / 0.036$} \\
\hline Parameters & $z$ & $o$ & $u$ & $z$ & $o$ & $u$ & $z$ & 0 & $u$ \\
\hline Peak 1 & $1.85(10)$ & $0.54(11)$ & $0.10(f)$ & $1.72(6)$ & $0.73(8)$ & $0.10(f)$ & $1.70(4)$ & $0.80(7)$ & $0.10(f)$ \\
\hline Peak 2 & $2.71(3)$ & $3.54(12)$ & $0.10(f)$ & $2.66(2)$ & $3.29(7)$ & $0.10(f)$ & $2.62(2)$ & $3.14(6)$ & $0.10(f)$ \\
\hline Peak 3 & $3.75(4)$ & $3.53(6)$ & $0.10(f)$ & $3.70(2)$ & $2.88(14)$ & $0.15(f)$ & $3.64(2)$ & $2.51(6)$ & $0.10(f)$ \\
\hline Peak 4 & $4.81(3)$ & $4.68(33)$ & $0.31(3)$ & $4.80(1)$ & $3.43(17)$ & $0.28(3)$ & $4.79(2)$ & $3.10(13)$ & $0.31(2)$ \\
\hline Peak 5 & 7.39(1) & $2.46(17)$ & $0.36(3)$ & $7.39(1)$ & $1.33(11)$ & $0.23(5)$ & $7.34(2)$ & $0.94(5)$ & $0.10(f)$ \\
\hline
\end{tabular}
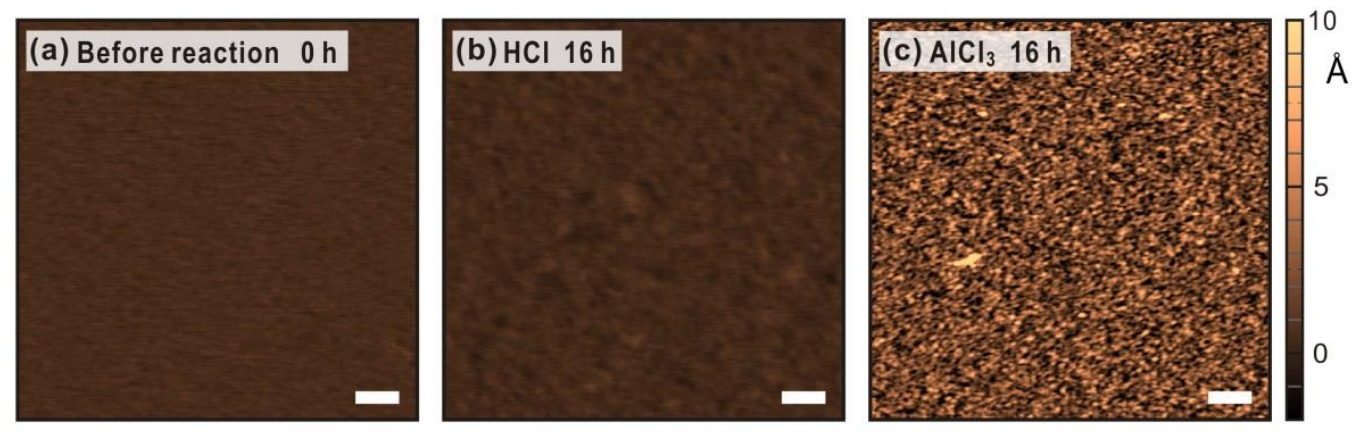

Figure S8. Atomic force microscopy images of the muscovite (001) surface before (a) and after reaction with $\mathrm{pH}$ 4.2 solutions of $\mathrm{HCl}$ and $100 \mu \mathrm{M} \mathrm{AlCl}_{3}$ (b and c, respectively) for $16 \mathrm{~h}$. The rms roughness values were $0.3,0.3$, and $2.1 \AA$, for a-c, respectively.

\section{SI references}

S1. Deer, W. A.; Howie, R. A.; Zussman, J. An Introduction to the Rock-Forming Minerals; 2nd ed.; John Wiley \& Sons, Inc.: New York, NY, 1992.

S2. Corbató, C. E.; Tettenhorst, R. T.; Christoph, G. G. Clays Clay Miner. 1985, 33, 71.

S3. Lee, S. S.; Nagy, K. L.; Fenter, P. Geochim. Cosmochim. Acta 2007, 71, 5763.

S4. Fenter, P. A. In Application of Synchrotron Radiation in Low-Temperature Geochemistry and Environmental Science, Reviews in Mineralogy and Geochemistry; Fenter, P. A., Rivers, M. L., Sturchio, N. C., Sutton, S. R., Eds.; Geochemical Society and Mineralogical Society of America: Washington DC, 2002; Vol. 49, p 149.

S5. Wilson, A. J. C. International Tables for Crystallography, vol. C: Mathematical, Physical, and Chemical Tables; Dordrecht: Kluwer Academic Publishers: Dordrecht, 1992.

S6. Cheng, L.; Fenter, P.; Nagy, K. L.; Schlegel, M. L.; Sturchio, N. C. Phys. Rev. Lett. 2001, 87, 156103. 
S7. Schlegel, M. L.; Nagy, K. L.; Fenter, P.; Cheng, L.; Sturchio, N. C.; Jacobsen, S. D. Geochim. Cosmochim. Acta 2006, 70, 3549.

S8. Lee, S. S.; Park, C.; Fenter, P.; Sturchio, N. C.; Nagy, K. L. Geochim. Cosmochim. Acta 2010, 74, 1762.

S9. Park, C.; Fenter, P. A. J. Appl. Crystallogr. 2007, 40, 290.

S10. Lee, S. S.; Nagy, K. L.; Park, C.; Fenter, P. Environ. Sci. Technol. 2009, 43, 5295.

S11.Cross, J. O.; Newville, M.; Rehr, J. J.; Sorensen, L. B.; Bouldin, C. E.; Watson, G.; Gouder, T.; Lander, G. H.; Bell, M. I. Phys. Rev. B: Condens. Matter 1998, 58, 11215.

S12. Waseda, Y. Novel Application of Anomalous (Resonance) X-ray Scattering for Structural Characterization of Disordered Materials; Springer: New York, 1984. 